\title{
On the use of acoustic data to characterise the thermohaline stratification in a tropical ocean
}

\author{
Ramilla Vieira Assunção ${ }^{1,2}$, Anne Lebourges-Dhaussy ${ }^{2}$, Alex Costa da Silva ${ }^{1}$, Bernard Bourlès ${ }^{3}$, \\ Gary Vargas ${ }^{4}$, Gildas Roudaut ${ }^{2}$, Arnaud Bertrand ${ }^{1,4,5}$ \\ $5 \quad{ }^{1}$ Laboratório de Oceanografia Física Estuarina e Costeira, Depto. Oceanografia, UFPE, Recife, Pernambuco, Brazil \\ ${ }^{2}$ Institut de recherche pour le développement (IRD), UMR 6539 LEMAR Ifremer, Université de Bretagne Occidentale, \\ Technopole Brest Iroise, Plouzané, France \\ ${ }^{3}$ Institut de recherche pour le développement (IRD), IMAGO, Plouzané, France \\ ${ }^{4}$ Universidade Federal Rural de Pernambuco, Recife-PE, Brazil \\ $10{ }^{5}$ Institut de recherche pour le développement (IRD), MARBEC, Université Montpellier, Ifremer, IRD, Sète, France
}

Correspondence to: Ramilla V. Assunção (ramillavieira@hotmail.com)

\begin{abstract}
The use of active acoustic to monitor abiotic structures and processes in the ocean have been gaining ground in oceanography. In some systems, acoustics allow the robust estimation of the depth of the pycnocline or thermocline either directly or indirectly when the physical structures drive the one of organisms. Here, we examined the feasibility of extracting the thermohaline structure (mixed-layer depth, upper and lower thermocline) from echosounder data collected in the oligotrophic Southwestern tropical Atlantic region at two seasons (spring and fall), more precisely in two areas with different thermohaline conditions, at both day and night. For that, we tested three approaches: (i) the vertical extension of the epipelagic community; (ii) the use of acoustic gradients; and (iii) a cross-wavelet approach. Results show that, even if the thermohaline structure impacts the vertical distribution of acoustic scatters, the resultant structuring did not allow for a robust estimation of the thermohaline limits indicating that other oceanographic or biological processes are acting. This result prevents for a fine-scale representation of the upper-layer turbulence from acoustic data. However, studying the proportion of acoustic biomass within each layer provides interesting insights on ecosystem structure in different thermohaline, seasonal and diel scenarios.
\end{abstract}

\section{Introduction}

The vertical structure of the upper ocean is primarily regulated by temperature and salinity, which together control the water column density structure so called thermohaline structure (Sprintall and Cronin, 2010). The thermohaline structure of the upper ocean can be divided into layers associated to different features: (i) the mixed-layer (ML); (ii) the thermocline, halocline and pycnocline; and (iii) the barrier layer (BL), which is the layer between thermocline and pycnocline induced by salinity (de Boyer Montégut et al., 2007; Sprintall and Cronin, 2010). The presence or absence of these layers as well as their properties (strength and morphology) depend on ocean-atmosphere interactions, hydrodynamic processes, and the influence of flow-topography (Araújo et al., 2011; Pailler et al., 1999; Assunção et al., 2020; Silva et al., 2021). The thermohaline structure drives most near-surface oceanic processes, including the control of gases and heat fluxes and momentum between ocean-atmosphere (Mignot et al., 2009; Miller, 1976) or the nutrient availability in the photic layer (Chen et al., 2018; Rippert et al., 2015). The modulation of the pycnocline allows identifying a variety of turbulent processes along scale including internal wave ( 100 m to $10-15 \mathrm{~km}$; Munk, 1981), submesoscale ( 1-20 km; e.g. fronts and filaments; Tomas et al., 2008) and mesoscale ( 20-100 km; e.g. 
eddies) activity (Bertrand et al., 2014; Grados et al., 2016). These processes modulate the concentration and distribution of marine organisms, shaping the dynamics of ecosystems (Lévy et al., 2012; Bertrand et al., 2014).

Ocean thermohaline structure is classically derived from in situ measurements (e.g., Tsuchiya et al., 1994), reanalysis products (e.g., climatology; Gaillard et al., 2016) or ocean models (e.g., Venancio et al., 2020). In situ observations from CTD, XBT, Argo profiles, and thermistors (Maze et al., 2017; Wijesekera and Boyd, 2001; Woods, 1968) provide high vertical resolution information but at discrete stations. They allow for process description from large scales to mesoscales, but not at smaller scales. For that, high resolution data are necessary. Within this perspective, active acoustic is a powerful tool since echosounders can capture fine-scale oceanographic structures typically attributed to biological scattering or turbulent structures (Bertrand et al., 2014; Klymak and Moum, 2003; Lavery et al., 2003; Pingree and Mardell, 1985; Stranne et al., 2018; Trevorrow, 1998). Indeed, acoustics allow covering large areas with a single signal providing continuous (along the route of the vessel and/or per sampling station) and high resolution on a variety of biotic (Benoit-Bird and Lawson, 2016; Bertrand et al., 2014) and abiotic properties such as the oxycline (Bertrand et al., 2010), internal waves (Gentil et al, 2021; Grados et al., 2016; Holbrook et al., 2009; Holbrook and Fer, 2005; Orr et al., 2000), submesoscale to mesoscale eddies (Biescas et al., 2008; Grados et al., 2016; Ménesguen et al., 2012), thermocline (Ker et al., 2016; Stranne et al., 2018) and thermohaline staircases (Biescas et al., 2008; Fer et al., 2010; Ross and Lueck, 2005; Stranne et al., 2017).

The accuracy of detection and monitoring of abiotic structures and processes by active acoustics depends on (i) the frequency applied; (ii) how well defined the structures of interest are (e.g. narrower thermoclines are more likely to be detected; weak density contrast at the base of the mixed layer decreases the chances of detection); (iii) ecosystem productivity (i.e. the amount and intensity of biological scatters); and (iv) the dominance of the biological backscatter (Ker et al., 2016; Pensieri and Bozzano, 2017; Stranne et al., 2018).

In the highly productive northern Humboldt Current system off Peru, where a shallow and intense oxygen minimum zone is present, echosounder data have been successfully used to monitor the depth of the upper oxycline, which matches the pycnocline (Bertrand et al., 2014, 2010; Grados et al., 2016). This allowed describing the variety of physical turbulent structures at scales ranging from the internal waves to the mesoscale and their further impacts on the distribution of organisms from plankton to top predators (Bertrand et al., 2014).

Thermohaline structuring as well as oxygen minimum zones play an important role in the vertical distribution of epipelagic and mesopelagic organisms (mainly zooplankton, cephalopods and small fishes). The vertical extension of the epipelagic community (VEEC) has been defined, primarily, in ocean regions where the oxygen minimum zones act as a barrier for most marine species (Criales et al., 2008; Ayón et al., 2008a; Bertrand et al., 2010). In these regions, the depth of the VEEC $\left(Z_{\mathrm{VEEC}}\right)$ has been defined as the depth where $98 \%$ of the cumulative sum (integrated downward from $10 \mathrm{~m}$ depth) of the acoustic echoes ( $\mathrm{s}_{\mathrm{A}}$, nautical area scattering coefficient in $\mathrm{m}^{2} . \mathrm{nmi}^{-2}$, MacLennan et al., 2002) from epipelagic community was reached (Bertrand et al., 2010).

Here, following this method, plus two other approaches (acoustic gradient and cross-wavelet analysis), we investigate whether information on the variation of the thermohaline structure could be extracted from acoustic data in a less productive tropical system. For that, we used data acquired during two surveys in the Southwestern Tropical Atlantic (SWTA, Fig. 1). In this region, the western boundary current system (WBCS) formed by the North Brazil Undercurrent 

offshore, lies the South Equatorial Current System (SECS), which includes the central branch of the South Equatorial Current (cSEC) and the South Equatorial Undercurrent (SEUC) (Silva et al., 2021; Stramma and Schott, 1999). Both systems are characterized by the presence of a permanent pycnocline, varying spatially and seasonally in structure (thickness and depth of its upper and lower limits) and consequent strength (Assunção et al., 2020).

\section{Material and Methods}

\subsection{Data}

Data were collected during two multidisciplinary surveys "Acoustic along the BRAzilian CoaSt (ABRACOS)" performed off the coast of northeast Brazil (Fig. 1) aboard the French R/V Antea in austral spring (September - October 2015; Bertrand, 2015) and fall (April - May 2017, Bertrand, 2017).

85 Conductivity, temperature, depth and oxygen (CTDO) hydrographic profiles were acquired at 96 stations using a CTDO Seabird SBE911+ from the surface down to $1000 \mathrm{~m}$, or down to ten metres above the bottom depth. Conductivity, temperature, pressure, and dissolved oxygen accuracies are of $3 \mathrm{mS} / \mathrm{m}, 0.001{ }^{\circ} \mathrm{C}, 0.7 \mathrm{dbar}$, and $0.09 \mathrm{ml}$ $1^{-1}$, respectively. Here, we focus on the 52 CTDO profiles deeper than $300 \mathrm{~m}$ (Fig. 1; Bertrand, 2015; Bertrand, 2017). Acoustic data were acquired using four Simrad EK60 scientific echosounders operating continuously during transects and hydrological stations and connected to split-beam transducers working at 38, 70, 120 and $200 \mathrm{kHz}$. Due to its limited operational range $(150 \mathrm{~m})$, the $200 \mathrm{kHz}$ was not used in this study. Echosounders calibrations were performed according to Foote et al. (1987) using a tungsten carbide sphere at the start of each survey. Transmit powers were $1000,500,200$ and $90 \mathrm{~W}$ for the 38,70, 120 and $200 \mathrm{kHz}$ transducers, respectively. The pulse length was set to 0.512 msec for all frequencies providing a vertical resolution of the raw data of $\sim 10 \mathrm{~cm}$.

95 Acoustic data processing, including automatic cleaning and the removal of background, transient and impulsive noise along with the attenuated signals, was done using the Matecho software tool (version 20191213V6; Perrot et al., 2018). Matecho is an open source IRD (Institut de Recherche pour le Développement) tool based on the IFREMER (Institut Français de Recherche pour l'Exploitation de la Mer) Movies 3D software (Trenkel et al., 2009). To get the same vertical resolution than the CTDO, a high-resolution echo-integration on 1 ping per $1 \mathrm{~m}$ high cell was applied on $\mathrm{s}_{\mathrm{v}}$ samples (volume backscattering coefficient, $\mathrm{m}^{2} \cdot \mathrm{m}^{-3}$, Maclennan et al., 2002) with a threshold at $-100 \mathrm{~dB}$ applied to the $\mathrm{Sv}$ (volume backscattering strength, $\mathrm{dB}$ re $1 \mathrm{~m}^{-1}$ ) values. Signals from less than $10 \mathrm{~m}$ depth were suppressed, as they were dominated by transducer back lobe reflections from the water surface, the ship hull and by surface bubbles. At each station, the purpose was to compare the CTDO profiles with the corresponding mean acoustic profiles at the available frequencies. For that, we used 100 pings after the end of each cast of CTDO to avoid the possible noise induced by the descent and ascent of the CTDO and to ensure working on genuine day and night data since CTDO profiles were mostly performed during twilight periods. 


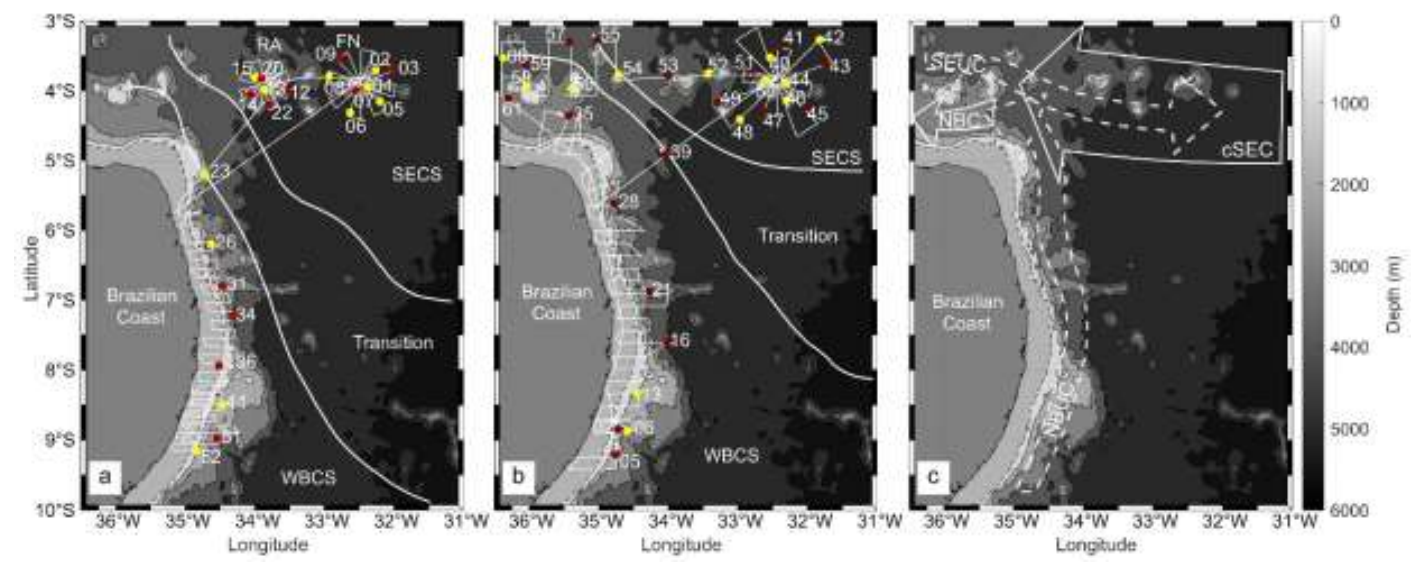

Figure 1: Survey tracks (black lines) of ABRACOS 1 (a) and ABRACOS 2 (b) surveys. Day (yellow circle) and night (red circle) CTDO stations used in this study. The continental shelf is represented in light grey; the dashed black line represents the shelf break ( $70 \mathrm{~m}$ isobath); other bathymetric contours (solid black lines) are by 1000 m intervals. RA: Rocas Atoll; FN: Fernando de Noronha archipelago. The boundaries (solid white lines) between the Western Boundary Current System (WBCS), the South Equatorial Current System (SECS), and the transitional area are plotted according to Assunção et al. (2020). The main currents (c) of each thermohaline system are: North Brazil Undercurrent (NBUC), North Brazil Current (NBC), central branch of South

115 Equatorial Current (cSEC) and South Equatorial Undercurrent (SEUC) (Dossa et al., 2021; Silva et al., 2021). The dotted arrows refer to the subsurface currents and the continuous arrows to the surface currents.

\subsection{Thermocline structure}

To describe the thermohaline structure, we have defined a series of parameters (Fig. 2a): the thermocline (upper and lower limits), the mixed-layer depth (MLD), and the barrier layer thickness (BLT). There is no consensus for such definitions, depending on the most suitable adjustment from the oceanographic conditions in each study region (Araújo et al., 2011; de Boyer Montégut et al., 2004; Holte and Talley, 2009; Ker et al., 2015, 2016). Here, we defined these limits using the criteria used by Assunção et al. (2020). The upper thermocline depth (UTD) is the depth at which $\partial_{\theta} / \partial_{z}=0.1^{\circ} \mathrm{C} / \mathrm{m}$. The lower thermocline depth (LTD) corresponds to the last depth below the UTD where the Brunt Väisälä frequency $\left(N^{2}\right.$, the buoyancy frequency squared), is of up to four orders of magnitude $\left(N^{2} \geq 10^{-4}\right)$. To determine the stability of water column, we used the Brunt Väisälä frequency, calculated according to the equation (1),

$N^{2}=-\frac{g}{\sigma_{0}} \frac{\partial_{\sigma_{Z}}}{\partial_{z}}$

where $g$ is the acceleration of gravity and $\sigma 0$ is a reference density at $10 \mathrm{~m}$ (Kim and Miller, 2007; Liu et al., 2016).

To define the MLD, we used the criteria from Sprintall and Tomczak (1992), i.e., the depth where the potential density

$130(\sigma)$ has increased, with respect to its value at the reference depth $\left(z_{0}=10 \mathrm{~m}\right)$, by an amount that corresponds to a drop in potential temperature by $0.5^{\circ} \mathrm{C}$, according to the equation (2),

$M L D=z\left(\partial_{z_{0}}+\frac{\partial_{\sigma \theta}}{\partial_{\theta}} \Delta_{\theta}\right)$ 
Finally, the barrier layer thickness (BLT) was calculated as the difference between the MLD and the UTD (BLT = MLD - UTD) (Lukas and Lindstrom, 1991).

\subsection{Linking acoustic profiles to thermohaline properties}

Here, we considered separately the diel period (day; night), the hydrodynamic systems (Western Boundary Current System - WBCS; South Equatorial Current System - SECS; Fig. 1; see Assunção et al., 2020), and the seasons (spring 2015; fall 2017). To determine if the thermohaline structure could be extracted from acoustic data, we tested two criteria ( $Z_{\mathrm{VEEC}}$ and acoustic gradient) and a cross-wavelet analysis approach (Fig. 2b, c, d). The methods have complementary potential, but each one is based on a specific hypothesis. First (Fig. 2b), we tested the method from Bertrand et al. (2010) to determine if the LTD could be derived from a specific value (or range) of the cumulative sum $(\%)$ of the acoustic echoes $\left(s_{A}\right.$, nautical area backscattering coefficient in $\left.\mathrm{m}^{2} . \mathrm{nmi}^{-2}\right)$ from upper ocean. The $s_{A}$ (a proxy for the acoustic biomass) is defined according to the equation (3),

$s_{A}=4 \pi(1852)^{2} \cdot \int_{z 1}^{z 2} s_{v} d z$

145 Second (Fig. 2c), we tested if the thermocline limits could be associated to specific volume backscattering strength gradient $\left(\partial_{S v} / \partial_{z}\right)$ values (or ranges) at each acoustic frequency $(38,70$ and $120 \mathrm{kHz})$. Gradient methods, as threshold ones, assume that there is a strong acoustic gradient marking the thermohaline layers interfaces. In fact, gradients are commonly used in a similar way to assess the MLD, thermocline or pycnocline depth (Assunção et al., 2020; Lukas and Lindstrom, 1991).

150 Finally (Fig. 2d), we applied a wavelet approach based on continuous wavelet transform (CWT), and cross-wavelet transform (XWT) to determine if the along-depth localised power variations in temperature $\left(x_{\partial_{\theta} / \partial_{z}}\right)$ and Sv $\left(y_{\partial_{S v}} / \partial_{z}\right)$ gradients match, allowing for determining the upper and lower limits of the thermocline. Cross-wavelet analysis is indeed a powerful method for testing proposed linkages between two signals, simultaneously in frequency (or scale) and time (or location) (Grinsted et al., 2004a; Muchebve et al., 2018). The wavelet power spectrum can be interpreted as depicting the local variance of a time/space series. The XWT is computed by multiplying the CWT of one timeseries by the complex conjugate of the CWT of the second time-series and depicts the local covariance between these series at each time/space and frequency. Therefore, the cross-wavelet power provides a quantification of the power similarities between two series (Aguiar-Conraria and Soares, 2014; Daubechies, 1992; Grinsted et al., 2004b; Tomás et al., 2016). 
(a)

$$
\begin{aligned}
& \text { Density }\left(\mathrm{kg} / \mathrm{m}^{3}\right) \\
& 24 \quad 25 \quad 26 \quad 27 \\
& \text { Temperature }\left({ }^{\circ} \mathrm{C}\right)
\end{aligned}
$$
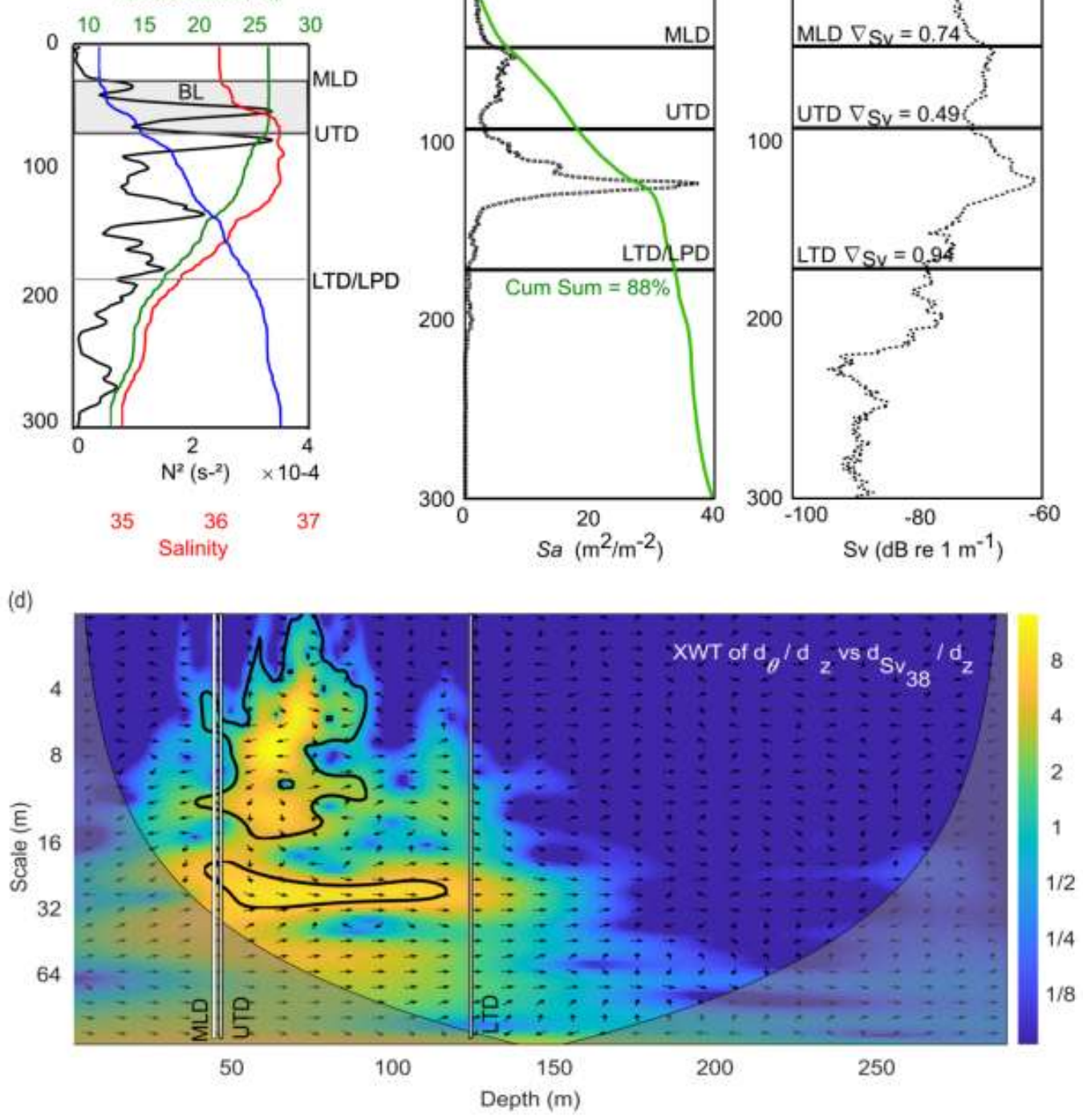

(b)

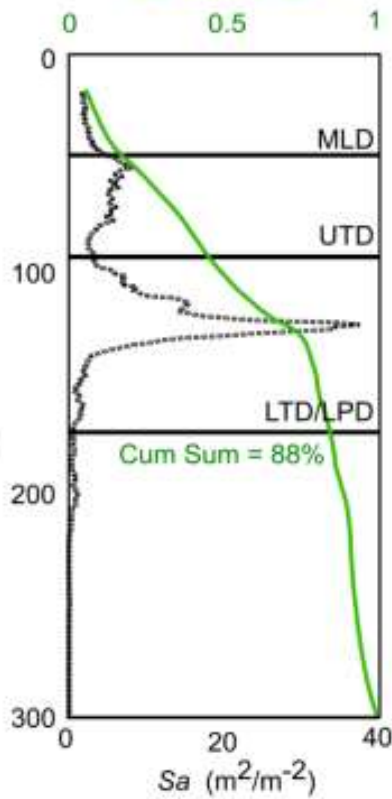

(c)

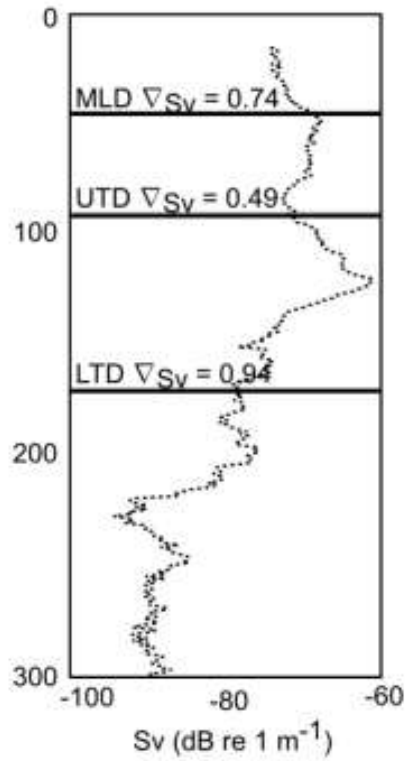




\section{Results and Discussion}

\subsection{Thermohaline limits vs. cumulative sum of the acoustic echoes}

170 The vertically cumulative sum (expressed as a percentage) of acoustic echoes $\left(\mathrm{s}_{\mathrm{A}}, \mathrm{m}^{2} . \mathrm{nmi}^{-2}\right)$ at 38, 70, 120 integrated downward from the surface to a depth of $300 \mathrm{~m}$, was evaluated at the three different thermohaline limits (MLD, UTD and LTD) (Fig. 3). Results show a wide variation of the cumulative sums of acoustic echoes at the three limits, whatever the frequency, for each hydrodynamics system or diel period (Figs. 3, 4 and 5). Even within a given hydrodynamic system where these limits, in particular the LTD, can be stable, the cumulative sum of acoustic echoes

175 was highly variable from one station to another (Fig. 4, see interquartile ranges). In addition, the variance was larger in the highly stratified SECS than in the WBCS, which is less stratified (Assunção et al., 2020). This result is rather opposite of what one might have expected. Indeed, according to previous studies (Bertrand et al., 2010), we could have expected more robust estimation in an area characterised by sharp density gradients. Therefore, this cumulative sum approach does not allow for a robust estimation of the thermohaline limits in the SWTA. However, studying the proportion of acoustic biomass within each layer provides interesting insights on ecosystem structure in different thermohaline, seasonal and diel scenarios. 
https://doi.org/10.5194/os-2021-101

Preprint. Discussion started: 19 November 2021

(c) Author(s) 2021. CC BY 4.0 License.

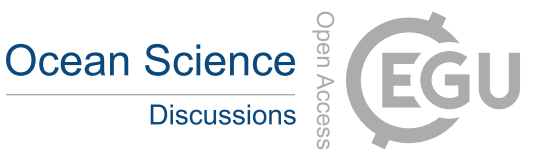

(c) (1)
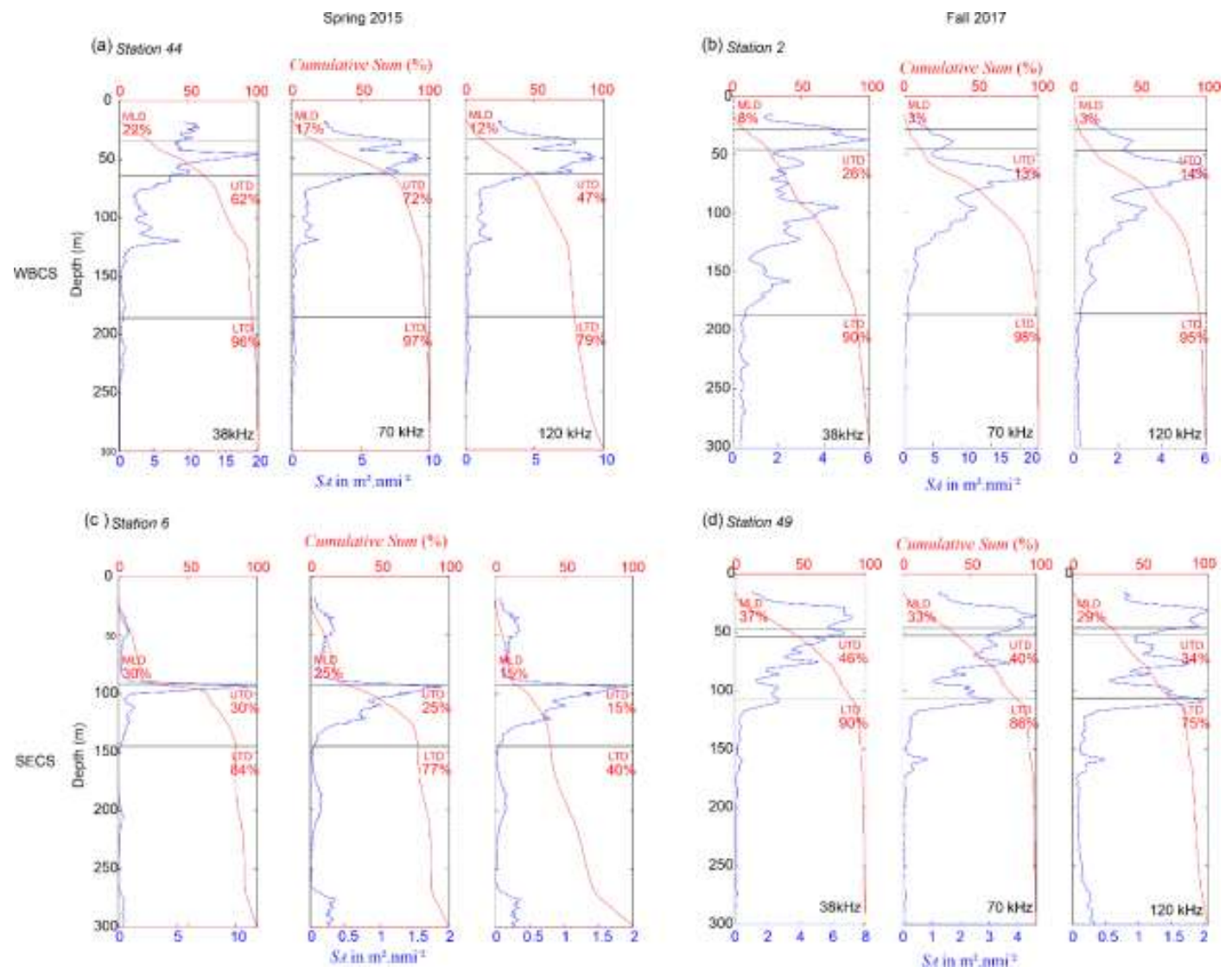

Figure 3. Examples of cumulative sum (\%) of the acoustic echoes $\left(\mathrm{s}_{\mathrm{A}}, \mathrm{m}^{2} \cdot \mathrm{nmi}^{2}\right)$ from surface to the MLD, UTD and LTD respective to the integration of acoustic echoes in the range $0-300 \mathrm{~m}$ in spring 2015 and fall 2017. MLD: mixed layer depth; UTD: upper thermocline depth; LTD: lower thermocline depth. 


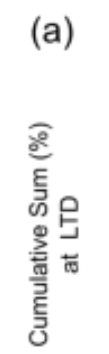

(c)
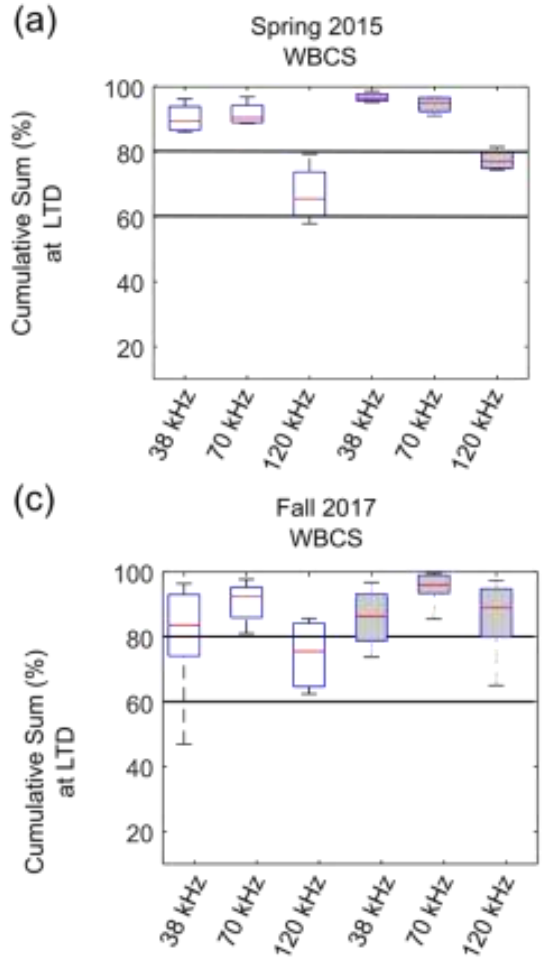

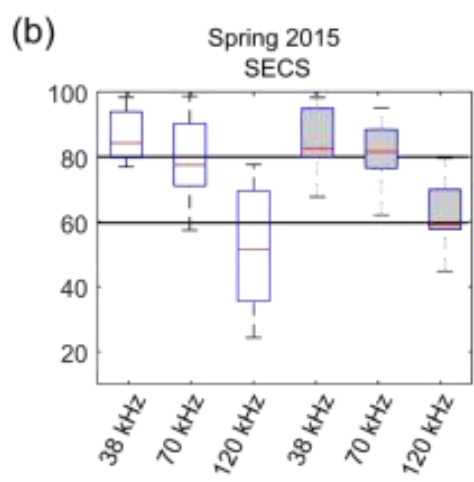

(d)
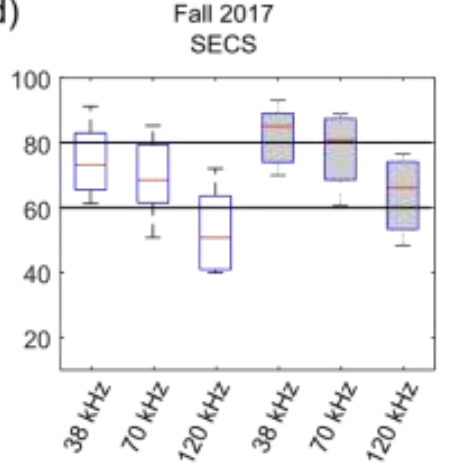

Figure 4. Boxplots of the cumulative sum $(\%)$ of the acoustic echoes $\left(\mathrm{s}_{\mathrm{A}}, \mathrm{m}^{2} \cdot \mathrm{nmi}^{-2}\right)$ from surface to lower thermocline depth respective to the integration of acoustic echoes in the range $0-300 \mathrm{~m}$ in (a) the WBCS in spring 2015; (b) the SECS in spring 2015; (c) the WBCS in fall 2017; (d) the SECS in fall 2017 (d). Day and night stations are represented by empty and grey boxes, respectively.

Except at $120 \mathrm{kHz}$ during the day in the SECS, at both seasons more than $60 \%$ of the upper ocean acoustic biomass was concentrated above the LTD (Figs. 4 and 5). The cumulative sums at the LTD increased at night (Figs. 4 and 5) due to vertical diel migration of mesopelagic organisms towards the epipelagic layer (e.g., Eduardo et al., 2020). Actually, the highest the cumulative sum (in particular at night and in spring), the lowest the inter-stations variability (Fig. 4, see interquartile ranges) so the highest is the possibility to estimate the LTD using the cumulative sum. Further, average $\mathrm{s}_{\mathrm{A}}$ cumulative sums at the MLD, UTD and LTD for both diel periods, hydrodynamics systems and seasons (spring and fall), reveal that most of the acoustic biomass was concentrated within the thermocline (i.e., between UTD and LTD) in both systems in fall. In spring, however, this pattern was only observed at day in the SECS. In both systems, in spring 2015, a large proportion of organisms (up to 60\% in the WBCS and SECS (only at night), respectively; less conspicuous at $120 \mathrm{kHz}$ ) inhabiting the water column were distributed above the thermocline, i.e., until the UTD. In the WBCS, this behaviour may be a strategy developed by organisms to limit the advection by the NBUC (below $\sim 100 \mathrm{~m}$ ), which is stronger at this season than in fall (Dossa et al., 2021). 


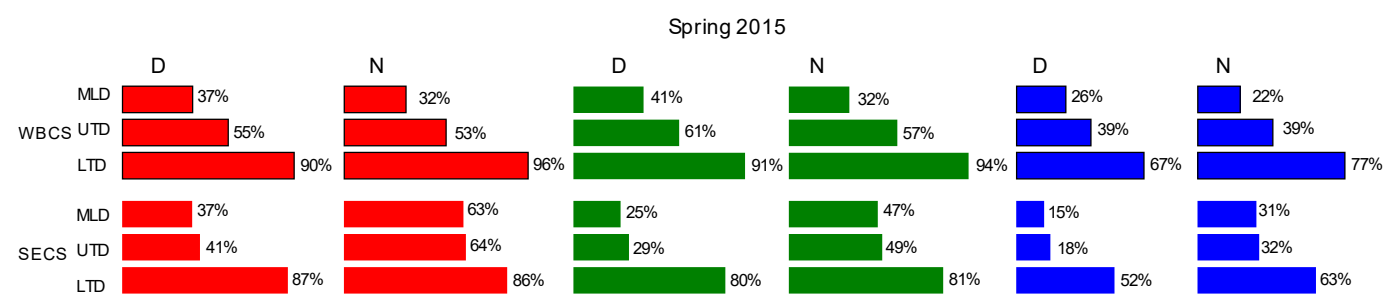

205 Figure 5. Mean cumulative sum (\%) of acoustic echoes $\left(\mathrm{s}_{\mathrm{A}}, \mathbf{m}^{2} \cdot \mathrm{nmi}^{-2}\right)$ respective to the integration of acoustic echoes in the range $0-300 \mathrm{~m}$ for each thermohaline layer limit: mixed-layer depth (MLD); upper thermocline depth (UTD) and lower thermocline depth (LTD). Results are presented according to the season (spring 2015; fall 2017), the diel period (D - day; $\mathrm{N}$ - night), the hydrodynamic system (WBCS; SECS) and the frequencies: $38 \mathrm{kHz}$ (red), $70 \mathrm{kHz}$ (green) and $120 \mathrm{kHz}$ (blue).

The acoustic biomass at the LTD were higher and with lower variability in the WBCS (Fig. 5), characterised by a smooth and thick thermocline (Assunção et al., 2020), than the SECS, whatever the season and diel period. Interestingly, in the SECS, characterised by a sharp and narrow thermocline and shallowest LTDs, a significant part of the biomass (up to 47\%) was distributed below the thermocline, most visible at $120 \mathrm{kHz}$ (fluid-like zooplankton

215 proxy; Stanton et al., 1998) (Fig. 5). These results lead us to hypothesize that in regions where the thermocline is highly stratified, and less mixed, some organisms avoid the layer of highest gradient. These results agree with previous studies (Lee et al., 2013) and are also consistent with the fact that, in the SECS in spring, zooplankton biomass is lower than in the WBCS, but organisms are larger (Figueiredo et al., 2020). Larger zooplankton are more likely to inhabit greater depths under more stratified conditions (Hampton et al., 2014).

\subsection{Thermohaline limits vs. acoustic backscattering gradient}

The value of Sv gradient differed according to the thermohaline limits in the WBCS (Fig. 6a, b). However, in the SECS, gradients were more alike between MLD and UTD, due to their proximity or overlap (Fig. 6c, d). Still, at all thermohaline limits (MLD, UTD and LTD), Sv gradients varied widely according to the frequency and the diel period, even within a given thermohaline system and season (Fig. 7). The largest interquartile ranges (considering the Sv gradient values of all stations) were observed for the UTD at day. Whereas the smallest interquartile ranges were more associated with the MLD and night. This seems to reflect the fact that during the day organisms present a more patchy distribution while at night they are organised over more homogeneous layers (e.g., Benoit-Bird et al., 2003). The smallest interquartile range was observed in spring in the WBCS at night with almost no variation among stations at 
70 and $120 \mathrm{kHz}$, then being the most promising condition for which a threshold may allow a robust estimation of the

UTD. However, considering the Sv gradient ranges observed for other frequencies and limits, we consider that the gradient criteria is not robust enough, since for a given limit (MLD, UTD or LTD) little or no variation between stations is expected, even in this specific case. Therefore, the application of specific Sv gradient value as a criterion to detect and track the thermohaline limits is likely unreachable in the SWTA.

Actually, the vertical distribution of pelagic organisms is often very patchy and acoustic scattering can vary by several orders of magnitude over few meters (Benoit-Bird, et al., 2003). In addition, the fact that gradients cannot be robustly associated to the physical structures confirms that the acoustic scatters we observed correspond to organisms and not to sole density structures. In some ecosystems, physical turbulence can be detected directly. For instance, in the Arctic Ocean, Stranne et al. (2018) successfully detected the MLD associated with the impedance contrasts. In such case, contrarily to ours, the number of biological scatters was low in the upper layers, facilitating the detection of genuine physically driven structures (Ker et al., 2015, 2016; Stranne et al., 2018).
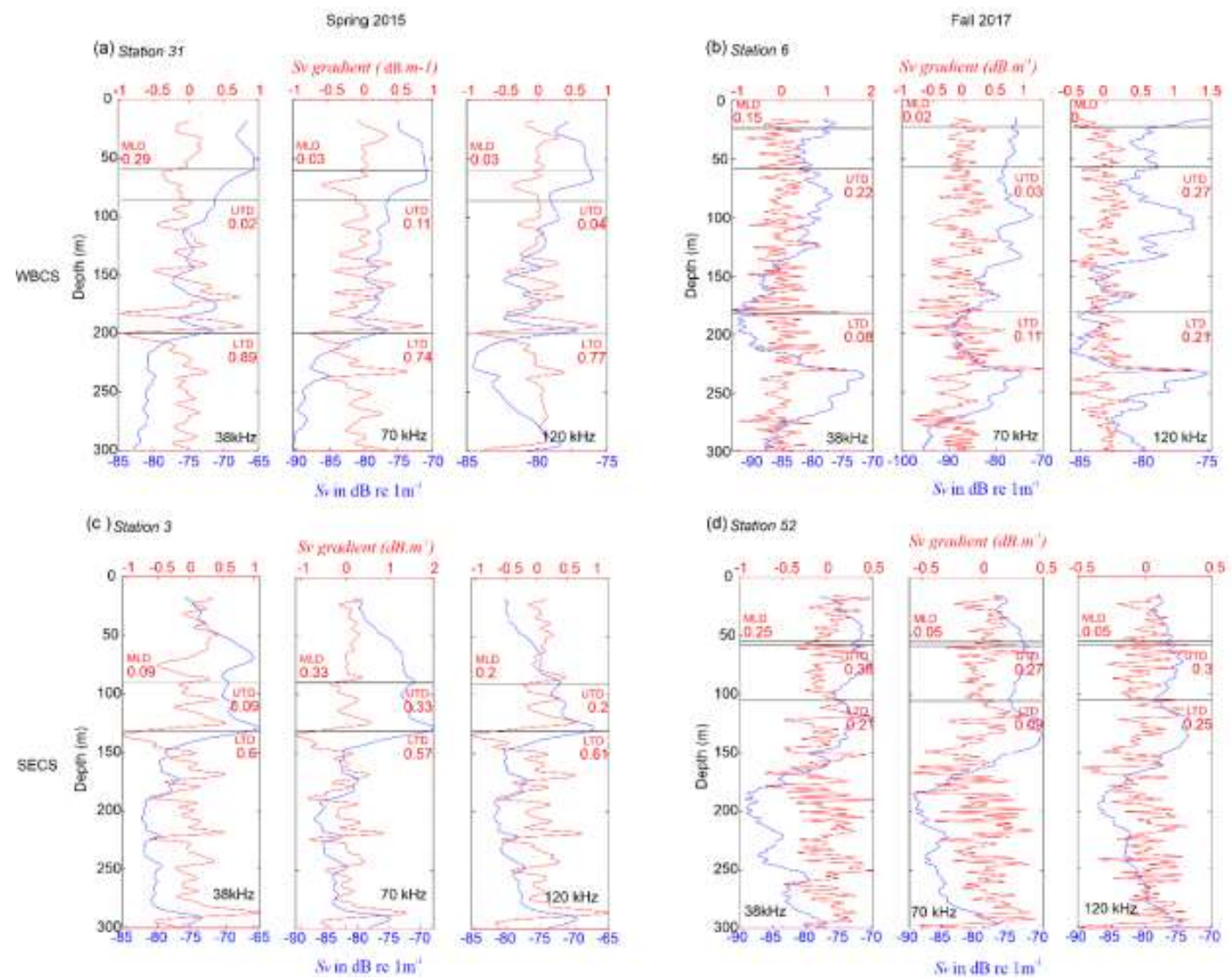

(d) Station 52

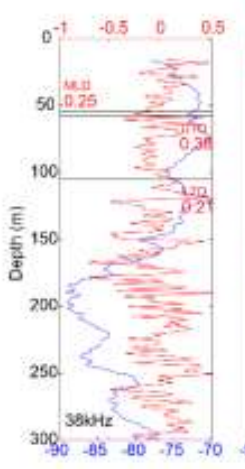

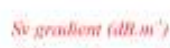

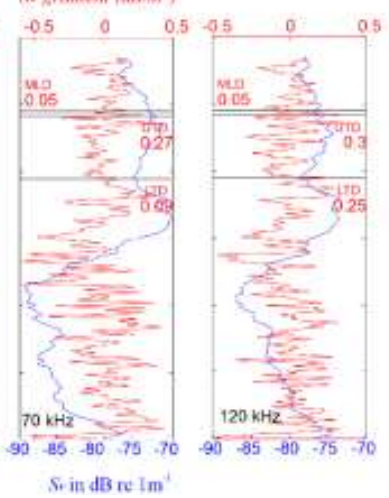

Figure 6. Examples of acoustic profiles (Sv, dB re $1 \mathrm{~m}^{-1}$ ) in spring 2015 (a, c) and fall 2017 (b, d). At each station, thermohaline structure is superimposed on the $\mathrm{Sv}$ profiles and their respective $\mathrm{Sv}$ gradients. The depth of 
greatest gradients is marked by a magenta asterisk. MLD: mixed layer depth; UTD: upper thermocline depth; LTD: lower thermocline depth.

(a)

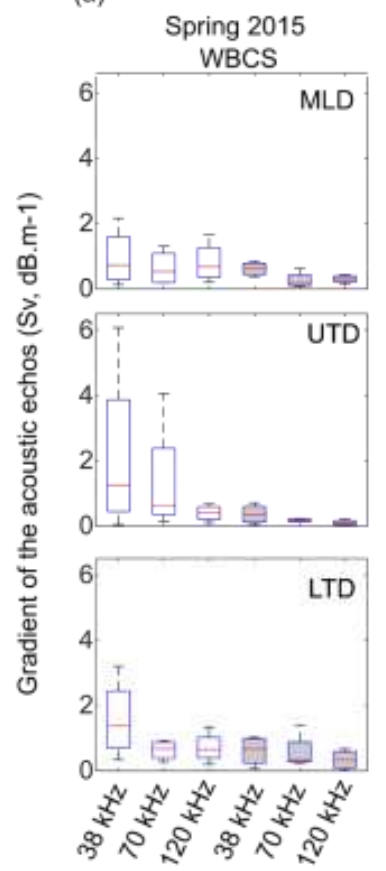

(b)
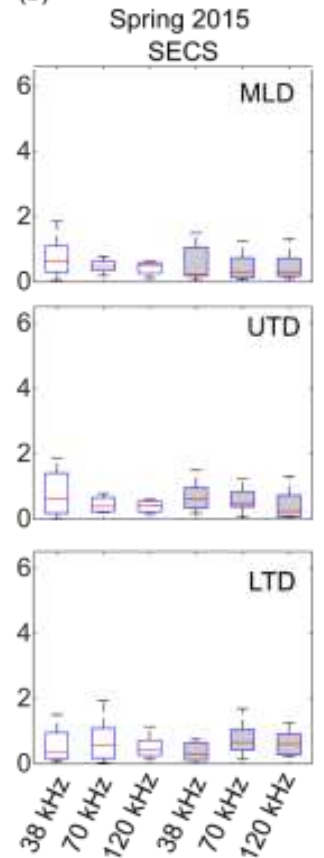

(c)

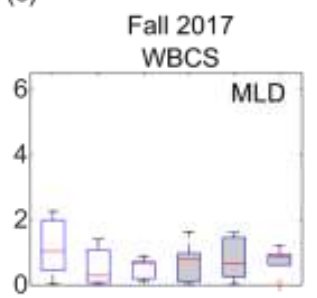

(d)

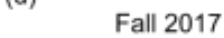

SECS
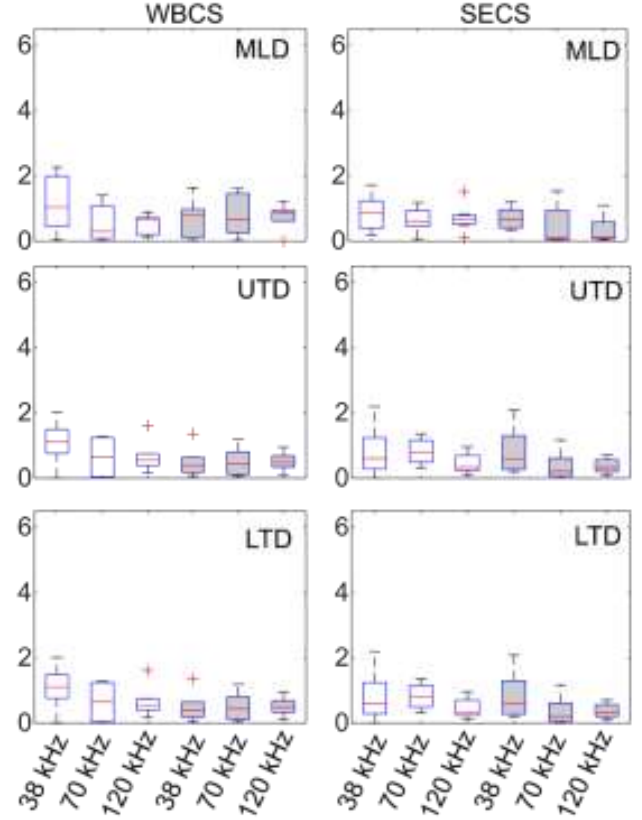

Figure 7. Boxplot of the acoustic gradient of $\mathrm{Sv}$ (in $\mathrm{dB}$ re $1 \mathrm{~m}^{-1}$ ) at the thermohaline vertical limits (MLD, UTD and LTD) according to the season (spring - a, b; fall - c, d), the thermohaline system (WBCS - a, c; SECS - b, d). For each case, frequencies $(38,70$ and $120 \mathrm{kHz}$ ) and diel period (day - empty box; night - grey box) are specified.

\subsection{Wavelet approach}

Here, we only present results obtained at $38 \mathrm{kHz}$ that are representative of the results observed at other frequencies (not shown).

The analysis of the continuous wavelet transforms (CWT, Figs. 8a, b and 9a, b) of the profiles of temperature gradient reveal that, as expected, the highest energy is encompassed within the thermocline. However, due to the differences in thermohaline structures, the signal energy of temperature gradient depicted more variable patterns in the WBCS, where the stratification is weak (Figs. 8a and 9a), than in the SECS (Figs. 8b and 9b). Sv gradient CWT patterns were less clear (Fig. 8c, d and 9c, d). The peaks of energy were not restricted to the thermocline and the scale varied between 4 and $32 \mathrm{~m}$ in the WBCS and 4 and $64 \mathrm{~m}$ in the SECS. As expected, we did not observe a well-defined pattern in the SECS (Figs. 8d and 9d). Sv gradient signals varied widely not only between systems, but also between stations and 
seasons. Nevertheless, the interaction between temperature and Sv signals becomes clearer when considering the cross-wavelet.

265 In both systems, cross-wavelet (XWT, Figs. 8e, f and 9e, f) reveal significant high common power mostly within the thermocline, generally in the $8-32 \mathrm{~m}$ scale. This pattern is also robust when considering the strong seasonal changes in the thermocline limits that were much shallower in fall than spring (Assunção et al., 2020). However, the common power locations did not always coincide with the thermocline limits, nor with the MLD. Moreover, the common power locations were highly variable between stations even in a given hydrodynamic system and season. Thereby, we cannot robustly draw the limits of the thermohaline layers with this method either. However, the cross-wavelet allows observing interesting relationships between the gradients of temperature and Sv. These gradients were mostly out of phase (arrow pointing left-biased). This indicates that Sv gradients did not match the position of temperature ones so that organisms formed more stable patches in the zones of strong thermic gradient (more static stability). One exception was observed in the WBCS in fall 2017 where signals were mostly in phase, and thermal and Sv gradients coincided (Fig. 9a, arrow pointing right-biased). 

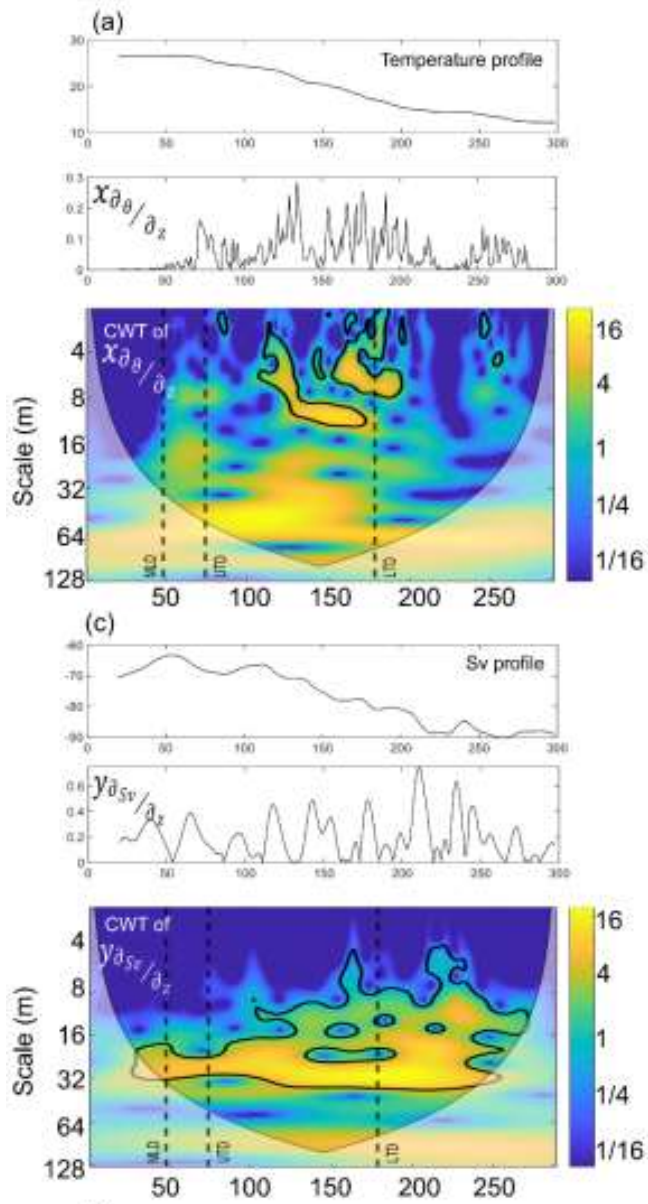

(e)

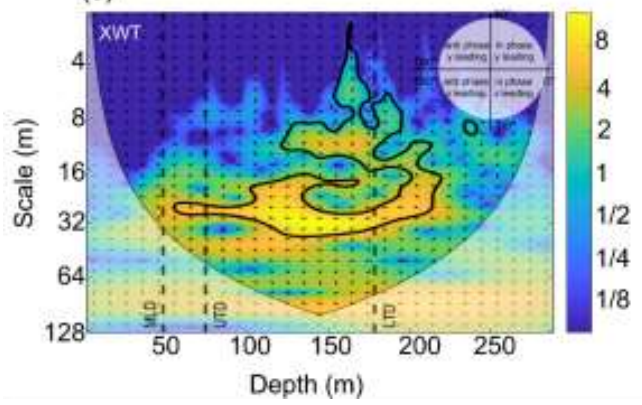

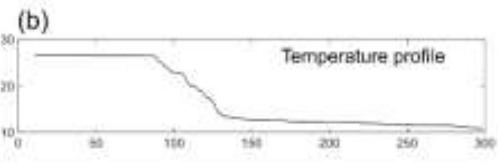
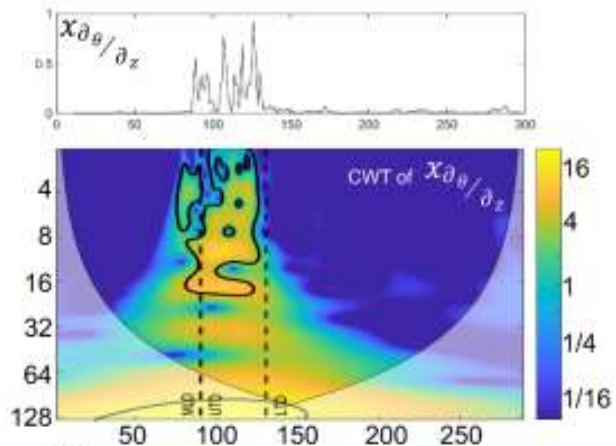

(d)
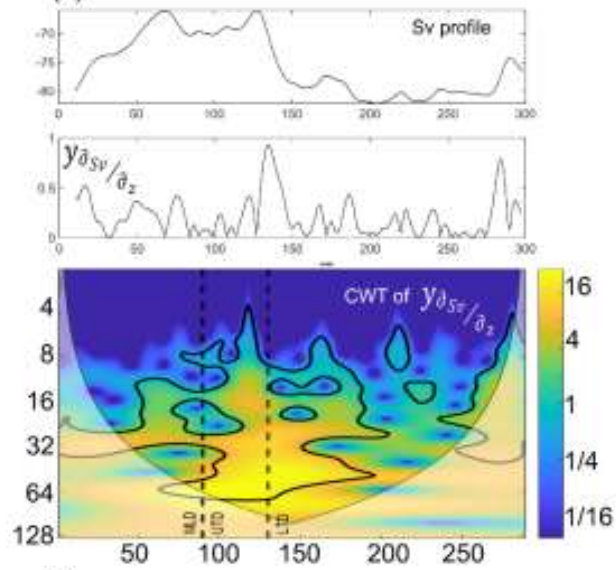

(f)

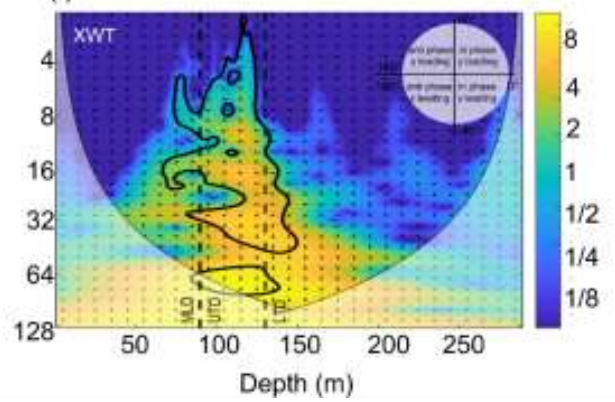

Figure 8. Examples of time/space series of temperature (a, b) and $\mathrm{Sv}$ at $38 \mathrm{kHz}$ (c, d) gradients and its continuous wavelet power spectrum from WBCS (a, c) and SECS (b, d) during spring 2015. Cross-wavelet transform (XWT) for $x_{\partial_{\theta} / \partial_{z}}$ and $y_{\partial_{S v} / \partial_{z}}$ from WBCS (e) and SECS (f). Arrows represent phase difference (with in-phase pointing right, anti-phase pointing left). The black contour encompasses regions with statistically significant signal at $95 \%$ confidence level. The cone of influence (COI) where edge effects might distort the picture is shown as a lighter shade. 

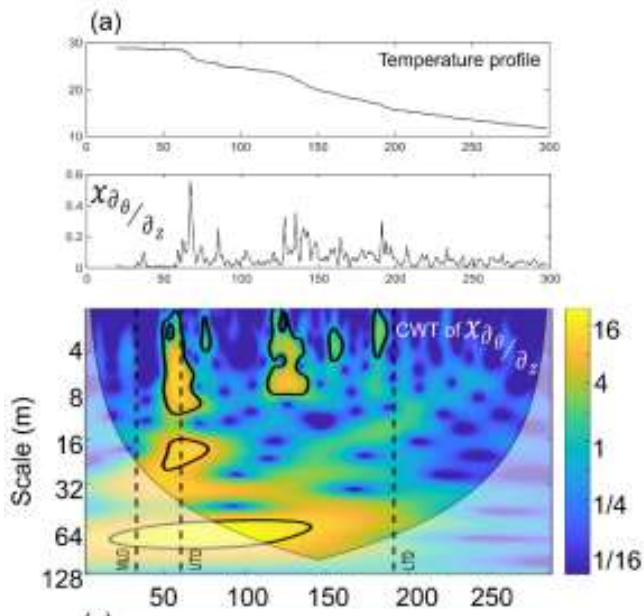

(c)
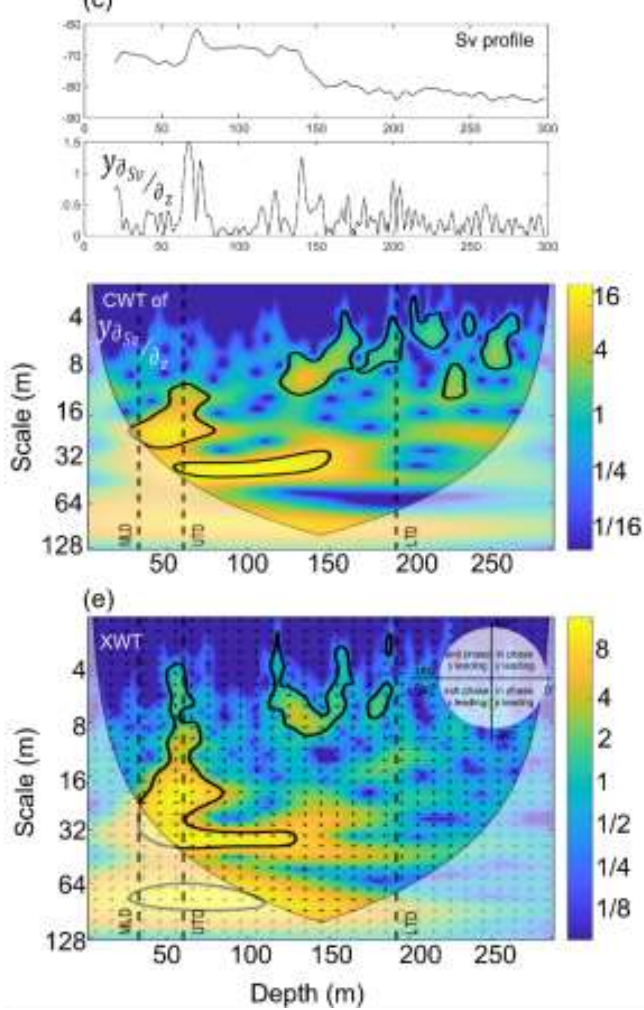
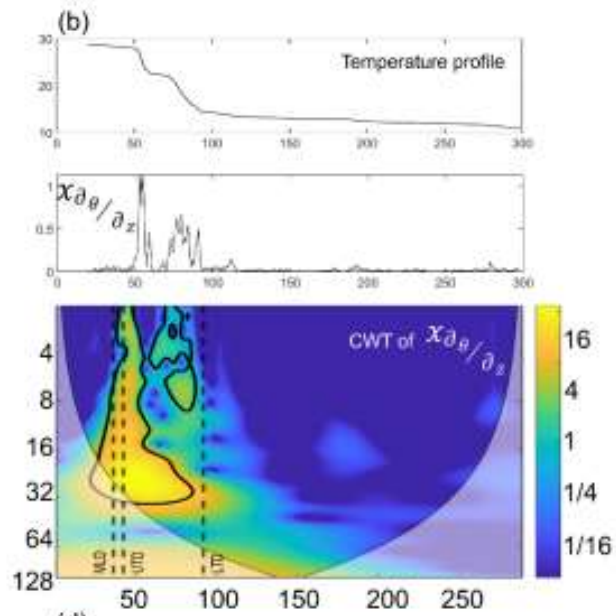

(d)
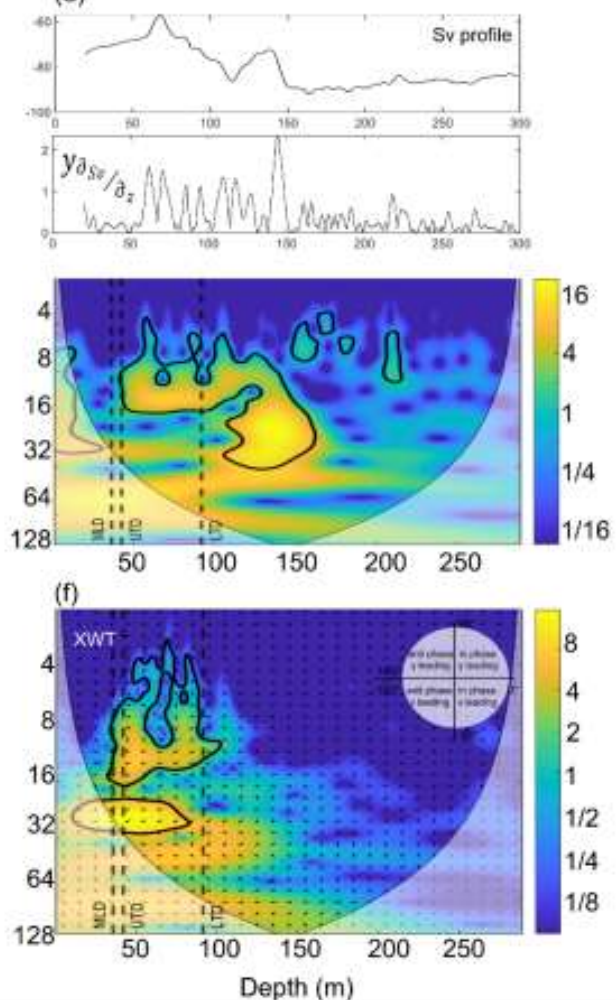

Figure 9. Examples of time/space series of temperature (a, b) and $\mathrm{Sv}$ at $38 \mathrm{kHz}$ (c, d) gradients and its continuous wavelet power spectrum from WBCS (a, c) and SECS (b, d) during fall 2017. Cross-wavelet transform (XWT) for $x_{\partial_{\theta} / \partial_{z}}$ and $y_{\partial_{S v} / \partial_{z}}$ from WBCS (e) and SECS (f). Arrows represent phase difference (with in-phase pointing right, anti-phase pointing left). The black contour encompasses regions with statistically significant signal at $95 \%$ confidence level. The cone of influence (COI) where edge effects might distort the picture is shown as a lighter shade. 


\section{Conclusion}

In this study, we aimed at verifying the feasibility to draw the vertical thermohaline structure from echosounder data, based on biological scattering or turbulent structures in an oligotrophic ecosystem. In principle, none of the three tested criteria (vertical distribution of the epipelagic community, gradient of acoustic energy and signal analysis between the thermal vertical and Sv gradients) allowed for a robust estimation of the thermohaline structure. From the analysis of the vertical integration (cumulative sum) of acoustic echoes, we expected that the thermocline could act as a natural barrier in the vertical distribution of organisms, mainly small mesopelagic fishes and zooplankton, as observed in the northern Humboldt Current system off Peru where a strong oxygen minimum zone is present (Bertrand et al., 2010). On the contrary, even in a given hydrodynamic system (WBCS and SECS) and season (spring and fall), we could not identify specific cumulative sums or gradient of echoes fitting thermohaline limits, including at night. In addition, according to the oceanscape, highest acoustic biomasses were not systematically associated with the thermocline, indicating that other oceanographic or biological processes may be acting.

Although we could not robustly detect the thermohaline vertical structure from acoustic scatters using these approaches, we revealed a variety of oceanscapes with different responses in terms of organisms vertical distribution. For example, in regions where the thermocline is highly stratified, and less mixed, a large amount of organisms seemed to avoid the layers of highest gradient. However, those organisms seeking more stable depths in the water column showed less variability in acoustic response, i.e., they tended to cluster in more stable patches. Further fine scale analyses involving other biogeophysical (e.g., currents and oxygen concentration) and biological (e.g., working with specific groups of acoustically discriminated organisms) factors need to be achieved to further understand the processes involved in the vertical structuring of the epipelagic community.

\section{Author contribution}

RA, GV and GR performed the data curation and software. RA, AB and ALD performed the formal analysis. RA prepared the manuscript with contributions to conceptualisation from all co-authors.

\section{Competing interests}

315 The authors declare that they have no known competing financial interests or personal relationships that could have appeared to influence the work reported in this paper.

\section{Acknowledgements}

We acknowledge the French oceanographic fleet for funding the at-sea survey and the officers and crew of the R/V Antea for their contribution to the success of the operations during the ABRACOS cruises. The Conselho Nacional de 320 Desenvolvimento Científico e Tecnológico (CNPq) by supported through a PhD scholarship grant for Assunção, Ramilla V. This work is a contribution to the International Joint Laboratory TAPIOCA (www.tapioca.ird.fr), 


\section{References}

Smith, A. A., Carter, C., and Miller, B. B.: More test articles, J. Adv. Res., 35, 13-28, dAguiar-Conraria, L. and Soares, M. J.: The continuous wavelet transform: moving beyond uni- and bivariate analysis, J. Econ. Surv., 28(2), 344-375, doi:10.1111/joes.12012, 2014.

Araújo, M., Limongi, C., Servain, J., Silva, M., Leite, F. S., Veleda, D. and Lentini, C. A. D.: Salinity-induced mixed and barrier layers in the southwestern tropical Atlantic Ocean off the northeast of Brazil, Ocean Sci., 7(1), 63-73, doi:10.5194/os-7-63-2011, 2011

Assunção, R. V., Silva, A. C. da, Roy, A., Bourlès, B., Silva, C. H. S., Ternon, J.-F., Araújo, M. and Bertrand, A.: 3D characterisation of the thermohaline structure in the southwestern tropical Atlantic derived from functional data analysis of in situ profiles, Prog. Oceanogr., 187(December 2019), 102399, doi:10.1016/j.pocean.2020.102399, 2020. Benoit-Bird, K. J. and Lawson, G. L.: Ecological Insights from Pelagic Habitats Acquired Using Active Acoustic

Techniques, Ann. Rev. Mar. Sci., 8(1), 463-490, doi:10.1146/annurev-marine-122414-034001, 2016.

Bertrand, A.: ABRACOS cruise, RV Antea, , doi:10.17600/15005600, 2015.

Bertrand, A.: ABRACOS 2 cruise, RV Antea, , doi:10.17600/17004100, 2017.

Bertrand, A., Ballón, M. and Chaigneau, A.: Acoustic observation of living organisms reveals the upper limit of the oxygen minimum zone, PLoS One, 5(4), doi:10.1371/journal.pone.0010330, 2010.

340 Bertrand, A., Grados, D., Colas, F., Bertrand, S., Capet, X., Chaigneau, A., Vargas, G., Mousseigne, A. and Fablet, R.: Broad impacts of fine-scale dynamics on seascape structure from zooplankton to seabirds, Nat. Commun., 5(May), doi:10.1038/ncomms6239, 2014.

Biescas, B., Sallarès, V., Pelegrí, J. L., Machín, F., Carbonell, R., Buffett, G., Dañobeitia, J. J. and Calahorrano, A.: Imaging meddy finestructure using multichannel seismic reflection data, Geophys. Res. Lett., 35(11), L11609, doi:10.1029/2008GL033971, 2008.

Bourlès, B., Molinari, R. L., Johns, E., Wilson, W. D. and Leaman, K. D.: Upper layer currents in the western tropical North Atlantic (1989-1991), J. Geophys. Res. Ocean., 104(C1), 1361-1375, doi:10.1029/1998JC900025, 1999. de Boyer Montégut, C., Madec, G., Fischer, A. S., Lazar, A. and Iudicone, D.: Mixed layer depth over the global ocean: An examination of profile data and a profile-based climatology, J. Geophys. Res. C Ocean., 109(12), 1-20, doi:10.1029/2004JC002378, 2004.

de Boyer Montégut, C., Mignot, J., Lazar, A. and Cravatte, S.: Control of salinity on the mixed layer depth in the world ocean: 1. General description, J. Geophys. Res. Ocean., 112(6), 1-12, doi:10.1029/2006JC003953, 2007.

Chen, G., Peng, L. and Ma, C.: Climatology and seasonality of upper ocean salinity: a three-dimensional view from argo floats, Clim. Dyn., 50(5-6), 2169-2182, doi:10.1007/s00382-017-3742-6, 2018.

355 Daubechies, I.: Ten Lectures on Wavelets, Society for Industrial and Applied Mathematics., 1992.

Dossa, A. N., Silva, A. C. da, Chaigneau, A., Eldin, G., Araújo, M. and Bertrand, A.: Near-surface western boundary circulation off Northeast Brazil, Prog. Oceanogr., 190, 102475, doi:10.1016/j.pocean.2020.102475, 2021. 
Fer, I., Nandi, P., Holbrook, W. S., Schmitt, R. W. and Páramo, P.: Seismic imaging of a thermohaline staircase in the western tropical North Atlantic, Ocean Sci., 6(3), 621-631, doi:10.5194/os-6-621-2010, 2010.

360 Figueiredo, G. G. A. A. de, Schwamborn, R., Bertrand, A., Munaron, J.-M. and Le Loc'h, F.: Body size and stable isotope composition of zooplankton in the western tropical Atlantic, J. Mar. Syst., 212, 103449, doi:10.1016/j.jmarsys.2020.103449, 2020.

Foote, K. G., Knudsen, H. P. and Vestnes, G.: Calibration of acoustic instruments for fish density estimation: A practical guide, J. Acoust. Soc. Am., 83(2), 831-832, doi:10.1121/1.396131, 1987.

365 Gaillard, F., Reynaud, T., Thierry, V., Kolodziejczyk, N. and von Schuckmann, K.: In Situ-Based Reanalysis of the Global Ocean Temperature and Salinity with ISAS: Variability of the Heat Content and Steric Height, J. Clim., 29(4), 1305-1323, doi:10.1175/JCLI-D-15-0028.1, 2016.

Gentil, M., Floc'h, F., Meunier, T., Ruiz-Angulo, A., Roudaut, G., Perrot, Y. and Lebourges-Dhaussy, A.: Internal solitary waves on the NW African shelf: A heuristic approach to localize diapycnal mixing hotspots, Cont. Shelf Res., 370 226, 104492, doi:10.1016/j.csr.2021.104492, 2021.

Grados, D., Bertrand, A., Colas, F., Echevin, V., Chaigneau, A., Gutiérrez, D., Vargas, G. and Fablet, R.: Spatial and seasonal patterns of fine-scale to mesoscale upper ocean dynamics in an Eastern Boundary Current System, Prog. Oceanogr., 142, 105-116, doi:10.1016/j.pocean.2016.02.002, 2016.

Grinsted, A., Moore, J. C. and Jevrejeva, S.: Application of the cross wavelet transform and wavelet coherence to 375 geophysical time series, Nonlinear Process. Geophys., 11(5/6), 561-566, doi:10.5194/npg-11-561-2004, 2004a.

Holbrook, W. S. and Fer, I.: Ocean internal wave spectra inferred from seismic reflection transects, Geophys. Res. Lett., 32(15), 2-5, doi:10.1029/2005GL023733, 2005.

Holbrook, W. S., Fer, I. and Schmitt, R. W.: Images of internal tides near the Norwegian continental slope, Geophys. Res. Lett., 36(24), 1-5, doi:10.1029/2009GL038909, 2009.

380 Holte, J. and Talley, L.: A new algorithm for finding mixed layer depths with applications to argo data and subantarctic mode water formation, J. Atmos. Ocean. Technol., 26(9), 1920-1939, doi:10.1175/2009JTECHO543.1, 2009.

Hounsou-Gbo, G. A., Servain, J., Araújo, M., Martins, E. S., Bourlès, B. and Caniaux, G.: Oceanic Indices for Forecasting Seasonal Rainfall over the Northern Part of Brazilian Northeast, Am. J. Clim. Chang., 05(02), 261-274, doi:10.4236/ajcc.2016.52022, 2016.

385 Ker, S., Le Gonidec, Y., Marié, L., Thomas, Y. and Gibert, D.: Multiscale seismic reflectivity of shallow thermoclines, J. Geophys. Res. Ocean., 120(3), 1872-1886, doi:10.1002/2014JC010478, 2015.

Ker, S., Le Gonidec, Y. and Marié, L.: Multifrequency seismic detectability of seasonal thermoclines assessed fromARGO data, J. Geophys. Res. Ocean., 3741-3756, doi:10.1002/2015JC011228.Received, 2016.

Kim, H.-J. and Miller, A. J.: Did the Thermocline Deepen in the California Current after the 1976/77 Climate Regime

390 Shift, J. Phys. Oceanogr., 37(6), 1733-1739, doi:10.1175/jpo3058.1, 2007.

Klymak, J. M. and Moum, J. N.: Internal solitary waves of elevation advancing on a shoaling shelf, Geophys. Res. Lett., 30(20), 2003GL017706, doi:10.1029/2003GL017706, 2003.

Lavery, A. C., Chu, D. and Moum, J. N.: Measurements of acoustic scattering from zooplankton and oceanic microstructure using a broadband echosounder, ICES J. Mar. Sci., 67(2), 379-394, doi:10.1093/icesjms/fsp242, 2010. 

Bottom Cold Water of the southeastern Yellow sea: focus on its relationship with a temperature structure, Acta Oceanol. Sin., 32(9), 44-49, doi:10.1007/s13131-013-0351-z, 2013.

Liu, C., Köhl, A., Liu, Z., Wang, F. and Stammer, D.: Deep-reaching thermocline mixing in the equatorial pacific cold tongue, Nat. Commun., 7(May 2015), doi:10.1038/ncomms11576, 2016.

400 Lukas, R. and Lindstrom, E.: The mixed layer of the western equatorial Pacific Ocean, J. Geophys. Res., 96(S01), 3343, doi:10.1029/90JC01951, 1991.

MacLennan, D. N., Fernandes, P. G. and Dalen, J.: A consistent approach to definitions and symbols in fisheries acoustics, ICES J. Mar. Sci., 59(2), 365-369, doi:10.1006/jmsc.2001.1158, 2002.

Maze, G., Mercier, H., Fablet, R., Tandeo, P., Lopez Radcenco, M., Lenca, P., Feucher, C. and Le Goff, C.: Coherent

405 heat patterns revealed by unsupervised classification of Argo temperature profiles in the North Atlantic Ocean, Prog. Oceanogr., 151, 275-292, doi:10.1016/j.pocean.2016.12.008, 2017.

Ménesguen, C., Hua, B. L., Carton, X., Klingelhoefer, F., Schnürle, P. and Reichert, C.: Arms winding around a meddy seen in seismic reflection data close to the Morocco coastline, Geophys. Res. Lett., 39(5), 1-6, doi:10.1029/2011GL050798, 2012.

410 Mignot, J., de Boyer Montégut, C. and Tomczak, M.: On the porosity of barrier layers, Ocean Sci., 5(3), 379-387, doi:10.5194/os-5-379-2009, 2009.

Miller, J. R.: The Salinity Effect in a Mixed Layer Ocean Model, J. Phys. Oceanogr., 6(1), 29-35, doi:10.1175/15200485(1976)006<0029:TSEIAM>2.0.CO;2, 1976.

Muchebve, E., Nakamura, Y. and Kamiya, H.: Use of Wavelet Techniques in the Study of Seawater Flux Dynamics

415 in Coastal Lakes, in Wavelet Theory and Its Applications, InTech., 2018.

Orr, M. H., Haury, L. R., Wiebe, P. H. and Briscoe, M. G.: Backscatter of high-frequency (200 kHz) acoustic wavefields from ocean turbulence, J. Acoust. Soc. Am., 108(4), 1595-1601, doi:10.1121/1.1286883, 2000.

Pensieri, S. and Bozzano, R.: Active and Passive Acoustic Methods for In-situ Monitoring of the Ocean Status, in Advances in Underwater Acoustics, InTech., 2017.

420 Perrot, Y., Brehmer, P., Habasque, J., Roudaut, G., Behagle, N., Sarré, A. and Lebourges-Dhaussy, A.: Matecho: An Open-Source Tool for Processing Fisheries Acoustics Data, Acoust. Aust., 46(2), 241-248, doi:10.1007/s40857-0180135-x, 2018.

Peterson, R. G. and Stramma, L.: Upper-level circulation in the South Atlantic Ocean, Prog. Oceanogr., 26(1), 1-73, doi:10.1016/0079-6611(91)90006-8, 1991.

425 Pingree, R. D. and Mardell, G. T.: Solitary internal waves in the Celtic Sea, Prog. Oceanogr., 14(C), 431-441, doi:10.1016/0079-6611(85)90021-7, 1985.

Rippert, N., Baumann, K.-H. and Patzold, J.: Thermocline fluctuations in the western tropical Indian Ocean during the past $35 \mathrm{ka}$, , 30, 201-210, doi:10.1002/jqs.2767, 2015.

Ross, T. and Lueck, R.: Estimating turbulent dissipation rates from acoustic backscatter, Deep. Res. Part I Oceanogr. 
Silva, A. C. da, Chaigneau, A., Dossa, A. N., Eldin, G., Araújo, M. and Bertrand, A.: Surface circulation and vertical structure of upper ocean variability around Fernando de Noronha archipelago and Rocas atoll during spring 2015 and fall 2017, Front. Mar. Sci., doi:10.3389/fmars.2021.598101, 2021.

Sprintall, J. and Cronin, M. F.: Upper Ocean Vertical Structure, Encycl. Ocean Sci., 217-224, doi:10.1016/B978012374473-9.00627-5, 2010.

Sprintall, J. and Tomczak, M.: Evidence of the barrier layer in the surface layer of the tropics, J. Geophys. Res., 97(C5), 7305, doi:10.1029/92JC00407, 1992.

Stanton, T. K., Chu, D. and Wiebe, P. H.: Sound scattering by several zooplankton groups. II. Scattering models, J. Acoust. Soc. Am., 103(1), 236-253, doi:10.1121/1.421110, 1998.

440 Stramma, L. and Schott, F.: The mean flow field of the tropical Atlantic Ocean, Deep Sea Res. Part II Top. Stud. Oceanogr., 46(1-2), 279-303, doi:10.1016/S0967-0645(98)00109-X, 1999.

Stranne, C., Mayer, L., Weber, T. C., Ruddick, B. R., Jakobsson, M., Jerram, K., Weidner, E., Nilsson, J. and Gårdfeldt, K.: Acoustic mapping of thermohaline staircases in the arctic ocean, Sci. Rep., 7(1), 1-9, doi:10.1038/s41598-017-15486-3, 2017.

445 Stranne, C., Mayer, L., Jakobsson, M., Weidner, E., Jerram, K., Weber, T. C., Anderson, L. G., Nilsson, J., Björk, G. and Gårdfeldt, K.: Acoustic mapping of mixed layer depth, Ocean Sci., 14(3), 503-514, doi:10.5194/os-14-503-2018, 2018.

Tomás, R., Li, Z., Lopez-Sanchez, J. M., Liu, P. and Singleton, A.: Using wavelet tools to analyse seasonal variations from InSAR time-series data: a case study of the Huangtupo landslide, Landslides, 13(3), 437-450, doi:10.1007/s10346-015-0589-y, 2016.

Trenkel, V. M., Berger, L., Bourguignon, S., Doray, M., Fablet, R., Massé, J., Mazauric, V., Poncelet, C., Quemener, G., Scalabrin, C. and Villalobos, H.: Overview of recent progress in fisheries acoustics made by Ifremer with examples from the Bay of Biscay, Aquat. Living Resour., 22(4), 433-445, doi:10.1051/alr/2009027, 2009.

Trevorrow, M. V.: Observations of internal solitary waves near the Oregon coast with an inverted echo sounder, J. Geophys. Res. Ocean., 103(C4), 7671-7680, doi:10.1029/98JC00101, 1998.

Tsuchiya, M., Talley, L. D. and McCartney, M. S.: Water-mass distributions in the western South Atlantic; A section from South Georgia Island (54S) northward across the equator, J. Mar. Res., 52(1), 55-81, doi:10.1357/0022240943076759, 1994.

Venancio, I. M., Shimizu, M. H., Santos, T. P., Lessa, D. O., Portilho-Ramos, R. C., Chiessi, C. M., Crivellari, S., 460 Mulitza, S., Kuhnert, H., Tiedemann, R., Vahlenkamp, M., Bickert, T., Sampaio, G., Albuquerque, A. L. S., Veiga, S., Nobre, P. and Nobre, C.: Changes in surface hydrography at the western tropical Atlantic during the Younger Dryas, Glob. Planet. Change, 184, 103047, doi:10.1016/j.gloplacha.2019.103047, 2020.

Wijesekera, H. and Boyd, T. J.: Upper Ocean Heat and Freshwater Budgets, in Encyclopedia of Ocean Sciences, pp. 3079-3083, Elsevier., 2001.

465 Woods, J. D.: Wave-induced shear instability in the summer thermocline. [online] Available from: http://virtualecology.org.uk/docs/research/Woods1968.pdf (Accessed 7 June 2019), 1968. 